\title{
Best Paper Awards for 2013
}

During 2013, Birkhäuser (Springer) instituted three Best Paper Awards for papers published in Circuits, Systems and Signal Processing (see the announcement in the October 2013 issue of CSSP). These awards are being given out for the first time this year. Early this year, a call for nominations for these awards was sent out to all the Associate Editors inviting them to nominate those papers published in 2012 or 2013 in CSSP, which should be considered for these awards. A total of nine papers were nominated. A Selection Committee consisting of Dr. P. V. Ananda Mohan, Electronic Corporation of India Limited, Bangalore, India; Dr. Robert W. Newcomb of the University of Maryland, U.S.A.; Dr. Peng Shi of Victoria University, Australia; and Dr. Ahmad M. Soliman of Cairo University, Egypt, was set up to select the best paper in each category for the year 2013. The recipients for the Armen H. Zemanian Best Paper Award, given for the best paper published in 2013 in the areas of Circuits and Systems are M. C. Tripathy, K. Biswas, and S. Sen for their paper entitled "A Design Example of a Fractional-Order Kerwin-Huelsman-Newcomb Biquad Filter with Two Fractional Capacitors of Different Order", published in the August 2013 issue. The recipients for the Sydney R. Parker Best Paper Award, given for the best paper published in 2013 in the area of Signal Processing are B. K. Meher and P. K. Meher for their paper "An Efficient Look-Up Table-Based Approach for Multiplication over GF(2m) Generated by Trinomials", published in the December 2013 issue. The latter paper was also chosen for the M.N.S. Swamy Best Paper Award, which is given for the best paper published in 2012 or 2013 irrespective of the subject area. Each of these awardees will receive a certificate and a cash prize. I would like to congratulate the recipients of the three awards. I would also like to take this opportunity to thank all the nominators and especially, the members of Selection Committee for their time and effort in selecting the winners for the various awards. 